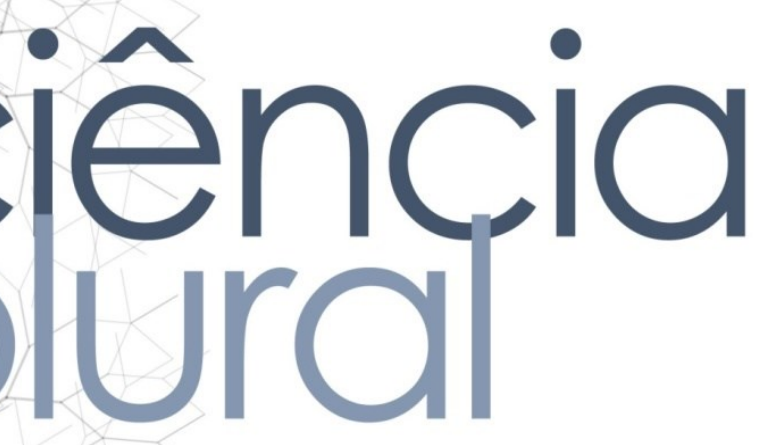

\title{
ANÁLISE DOCUMENTAL DOS SERVIÇOS DE SAÚDE BUCAL OFERTADOS À POPULAÇÃO INDÍGENA NO BRASIL
}

\section{Documentary analysis of the oral health services offered to the brazilian indigenous population}

Fernanda Izaura Rodrigues - Mestranda em Odontologia Preventiva Social da Universidade Estadual Paulista-UNESP, Araçatuba / SP - Brasil.Endereço: Rua José Bonifácio, 1193 -Bairro Vila Mendonça. CEP 16015-900 - Araçatuba / SP - Telefone: 18 3636-3942 - 18 99751-1097. E-mail: nandaiza@gmail.com

Cléa Adas Saliba Garbin - Doutora em Odontologia Legal. Professora Titular da Universidade Estadual Paulista-UNESP, Araçatuba / SP - Brasil. E-mail: cleagarbin@yahoo.com.br

Suzely Adas Saliba Moimaz - Doutora em Odontologia Preventiva e Social. Professora Titular da Universidade Estadual Paulista-UNESP, Araçatuba / SP - Brasil. E-mail: sasaliba@foa.unesp.br

Nemre Adas Saliba - Doutora em Odontologia Preventiva e Social. Professora Titular da Universidade Estadual Paulista-UNESP, Araçatuba / SP - Brasil. E-mail: nemre@unesp.foa.br raduada em Gestão em Sistemas e Serviços de Saúde da Universidade Federal do Rio Grande do Norte. Endereço Rua Itarantim, No 57 Pajuçara, 59132030 Natal/RN. E-mail: aline_grimberg@yahoo.com.br (84)99165-1011.

Autora responsável pela correspondência:

Fernanda Izaura Rodrigues. Mestranda em Odontologia Preventiva Social da Universidade Estadual PaulistaUNESP, Araçatuba / SP - Brasil.Endereço: Rua José Bonifácio, 1193 -Bairro Vila Mendonça. CEP 16015900 - Araçatuba / SP - Telefone: 18 3636-3942 - 18 99751-1097. E-mail: nandaiza@gmail.com 


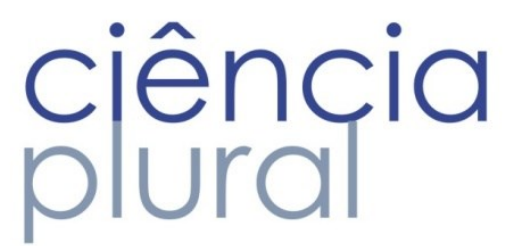

RESUMO

Introdução: Os povos indígenas do Brasil compõem um cenário diversificado do ponto de vista cultural. A garantia de assistência à saúde geral e bucal indígena, atualmente, foi estabelecida pelo Subsistema de Atenção à Saúde Indígena, integrado ao Sistema Único de Saúde. Objetivos: Analisar a política de saúde bucal inserida no subsistema de saúde indígena, evidenciando a sua evolução no processo histórico e legal. Metodologia: Trata-se de um estudo descritivo e exploratório, em que foram consultados decretos, leis e portarias, já com as recentes e respectivas mudanças na legislação. Discussão: Apesar dos avanços, há recorrentes disparidades ao analisarmos a saúde bucal indígena em comparação à população brasileira não indígena. Essa diferença é observada nos perfis de saúde indígena, os quais são relativos aos âmbitos nacionais e regionais, em uma combinação de fatores socioeconômicos, ambientais e políticos. Ao longo do tempo, a saúde indígena esteve sob responsabilidade de distintas instituições. Recentemente, um projeto de lei propôs a criação do Instituto Nacional de Saúde Indígena, com intuito de simplificar os processos administrativos. Conclusão: A trajetória da saúde bucal indígena brasileira é marcada por dissidências e existem bases jurídicas que garantem o acesso aos cuidados de saúde deste grupo, embora a descontinuidade das políticas impeça a integralidade das ações de saúde bucal.

Palavras-chave: Índios Sul-Americanos, Políticas Públicas, Saúde Bucal, Saúde de Populações Indígenas.

\begin{abstract}
Introducion: From a cultural point of view the Brazilian indigenous peoples compose a diversified cultural scenario. The guarantee of general and oral health assistance of indigenous people has been established by the Subsystem of Attention to Indigenous Health, integrated into the Brazilian Unified Health System. Objectives: To analyze the oral health policy inserted in the subsystem of indigenous health, evidencing its evolution in the historical and legal process. Methodology: It was a descriptive and exploratory study, in which decrees, laws and rules were consulted, with recent and relevant changes in legislation. Discussion: Despite the advances there are recurrent disparities when analyzing indigenous oral health in comparison to the nonindigenous Brazilian population. This difference is observed in indigenous health profiles, which are related to national and regional levels, in a combination of socioeconomic, environmental and political factors. Over the years, indigenous health has been under the responsibility of different institutions. Recently, a bill proposed the creation of the National Institute of Indigenous Health, in order to simplify administrative processes. Conclusion: The trajectory of Brazilian indigenous oral health is marked by dissidents and there are legal bases that guarantee the access to health care of this group, although the discontinuity of the policies blocks the integrality of oral health actions.
\end{abstract}

Key words: South American Indians, Public Policy, Oral Health, Health of Indigenous Peoples. 


\section{Introdução}

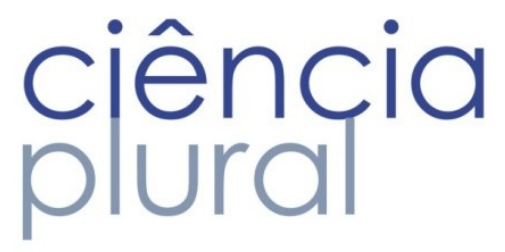

Os povos indígenas do Brasil compõem um cenário diversificado do ponto de vista cultural ${ }^{1}$. A partir do Censo Indígena de 20101', há no país, aproximadamente 900 mil membros dessa comunidade, dos quais 637 mil vivem em áreas indígenas, divididos entre 305 etnias. No Brasil, 98,7\% das terras indígenas estão concentradas na região norte e centro-oeste e pouco mais de $1 \%$ nas regiões sul, sudeste e nordeste 2 .

Nas regiões norte e centro-oeste, as aldeias são esparsas e de baixa densidade demográfica, o que implica dificuldade de acesso. Apesar deste obstáculo, 0 atendimento odontológico em área indígena é realizado tanto nas aldeias como nas Unidades Básicas de Saúde (UBS) dos polos-base, local onde estão instalados os consultórios odontológicos 3,4 .

A garantia de assistência que assegura a saúde geral e bucal indígena, atualmente, é estabelecida pelo Subsistema de Atenção à Saúde Indígena, integrado ao Sistema Único de Saúde (SUS), porém, a gestão administrativa é realizada pela Secretaria Especial de Saúde Indígena -SESAl, respeitando a crença e a cultura deste povo ${ }^{5}$.

Segundo Coimbra Júnior e Santos ${ }^{6}$, a coleta e a análise das informações demográficas são ainda bastante deficientes, de modo que necessitam de um sistema de estatística contínuo e confiável, que seja integrado aos sistemas nacionais de informação em saúde. Para outros autores, evidenciar os contrastes da situação da saúde indígena em relação aos outros segmentos da sociedade brasileira é um passo fundamental na busca da equidade social, de modo sempre efetivar e implementar determinadas políticas públicas ${ }^{6-7}$.

Existe no Brasil, de acordo com Moimaz, uma grande variação na prevalência de cárie dentária, devido principalmente ao contraste social e à grande extensão geográfica do país, porém, em relação à população indígena, desperta inquietação a escassez notória de informação - tanto quantitativa quanto qualitativa - e por razões evidentes: a geografia é um aspecto limitador.

Os bancos de dados são fundamentais para a compreensão dos aspectos comunitários, pois contribuem para a vigilância epidemiológica, para a produção de conhecimento e para a elaboração das estratégias de prevenção e promoção da saúde. A exiguidade de informações, principalmente considerando a singularidade da saúde indígena, gera inconstâncias no que tange às práticas de políticas da saúde, sendo 


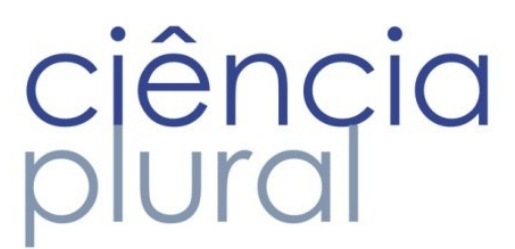

ainda agravadas pelas mudanças administrativas e legislativas. Sendo certo que 0 aspecto legislativo, sempre efêmero, tende a não ser preventivo no que diz respeito à proteção das minorias indígenas ${ }^{9}$.

O presente artigo tem como objetivo descrever a análise da série histórica e da legislação que rege a saúde bucal indígena, caracterizando-a, cronologicamente, desde os primeiros cuidados da saúde bucal, em conjunto com a saúde geral indígena, até a atualidade. Pretende-se, ainda, descrever a sua estrutura e funcionamento e gerar informações acerca das práticas voltadas à rede de serviços de saúde bucal indígena.

\section{Metodologia}

Este estudo é do tipo descritivo e exploratório, apoiado em pesquisa bibliográfica e documental ${ }^{10}$ acerca da história e da legislação da saúde bucal indígena e da evolução das práticas de políticas de saúde indigenista no Brasil, dos seus primórdios até os dias atuais. Foi realizado levantamento bibliográfico nas seguintes bases de dados científicas: Pubmed/Medline, SciELO, Scopus e LILACS, no período entre 1970 e 2016, empregando-se os seguintes descritores: oral health; dental caries; health policy; public policies; Indians; Indigenous population; Indigenous Populacion; Health of Indigenous Peaples; Indigenus Health Service; South American Indians; Indigenous health. As referências bibliográficas dos artigos identificados foram consultadas a fim de que fosse possivel encontrar possíveis artigos não compreendidos na pesquisa bibliográfica.

O arcabouço jurídico institucional definido pelo Sistema Único de Saúde é composto pelas Políticas de Saúde Bucal, pelo Subsistema de Atenção à Saúde Indígena - órgãos que regulamentam a questão operacional -, pela Secretaria Especial de Saúde Indígena, pela Fundação Nacional de Saúde e pela Fundação Nacional do Índio, locais onde foram examinados os seguintes documentos: Leis, Decretos, Portarias e Conferências.

As publicações que se configuram como textos completos e que foram incluídas à pesquisa apresentam temas relacionados: às políticas indigenistas, à saúde bucal e indígena no Brasil e a fatos que reconstituem a trajetória histórica e atual da política nacional de saúde indígena. Não houve restrições a idiomas e períodos de publicação, mas foram excluídos os periódicos contrários ao objetivo proposto bem como os textos incompletos.

Após leitura do material coletado, estes foram individualizados e analisados de acordo com a cronologia dos fatos abordados. A organização dos referidos dados compreendeu a análise legislativa ${ }^{11}$ dos mesmos, de modo que foram seguidas, portanto, as seguintes etapas: uma análise prévia, a partir das regras de abrangência; representatividade e relevância, seguindo pela demarcação do que será considerado como 


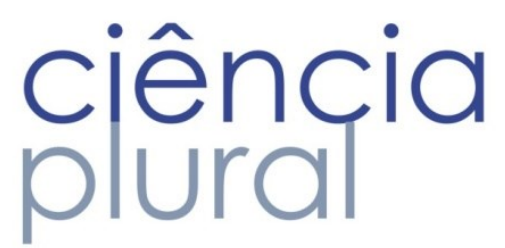

o corpus, ou seja, o tema central - saúde indígena, além da conclusão - onde os citados dados foram inseridos, de modo a identificar as unidades de registro.

\section{HISTÓRICO}

A partir do descobrimento do Brasil, foram encontrados relatos de dores e sofrimentos dentários na população indígena de modo geral. Naquela época, a assistência à saúde indígena era efetuada por meio de missões religiosas e, inicialmente, esses contatos eram feitos de forma violenta, provocando mortes, epidemias e maus-tratos 12,13 .

O Serviço de Proteção ao Índio (SPI) foi a primeira política pública indigenista do estado Brasileiro, através do Decreto-Lei $n^{0} 8.072^{14}$, e teve sua atuação até 1967, retirando da Igreja a responsabilidade em relação aos indígenas, garantindo, assim, a assistência médica. Esse período ficou conhecido como "Período Rondonista"15. Graças à atuação do médico sanitarista Noel Nutels, em 1956, foi implantado o Serviço de Unidades Sanitárias Aéreas (SUSA). Devido à sua experiência na assistência à saúde indígena, foi criado, em conjunto com o Correio Aéreo Nacional (CAN), um modelo de assistência aérea, com equipes volantes, contendo médicos, dentistas, enfermeiros e técnicos em saúde, possibilitando o acesso à saúde dos indígenas em regiões isoladas. O SUSA era vinculado ao Ministério da Saúde ${ }^{16,17}$.

A Fundação Nacional do Índio (FUNAI) foi criada na Ditadura Militar. Por força da Lei $n^{0} 5.371 / 67^{18}$ foi instituído um novo modelo de assistência à saúde indígena, vinculado ao Ministério do Interior. Posteriormente, no ano de 1973 foi publicado a Lei n. ${ }^{0} 6.001^{19}$, conhecida como Estatuto do Índio, que tinha como objetivo tutelar, regularizar a situação jurídica das minorias indígenas no Brasil, de modo a preservar a sua cultura e integrá-los de forma progressiva e harmoniosa ${ }^{20} \mathrm{em}$ detrimento da sua cultura sem prejuízo da administração do Conhecimento Tradicional Associado. O Estatuto do Índio exerceu um papel muito importante, possibilitando a entrada dos indígenas aos objetivos da FUNAI, assegurando uma participação ativa nos projetos e programas voltados às referidas comunidades ${ }^{19,20}$.

As ações de saúde pública brasileira geravam grande insatisfação e, apesar do Brasil estar naquele momento sob a égide de um regime político opressor, surgiu um movimento pela reforma do sistema. Foi um período muito intenso para a saúde no país ${ }^{21}$ e a Reforma Sanitária ficou conhecida como o percurso de reformulação e transformação da política institucional de saúde.

Consequentemente à Reforma Sanitária, em meados dos anos 80 , foram realizadas a $8^{\mathrm{a}}$ Conferência Nacional de Saúde, a $1^{\text {a }}$ Conferência Nacional de Saúde Bucal e a $1^{\text {a }}$ Conferência Nacional de Saúde do Índio22. Como resultado das discussões propostas nesses eventos, surgiu a proposição da criação de um sistema único de saúde, vinculado ao Ministério da Saúde, bem como surgiu a proposta da criação de uma 


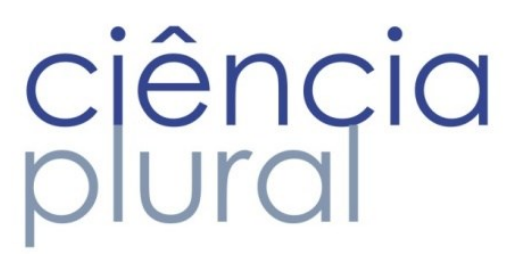

Política Nacional de Saúde Bucal e da Saúde do Índio, de forma que um único órgão possibilitasse a participação e o acesso da população à saúde. Os direitos foram reconhecidos com a aprovação da Constituição da República Federativa do Brasil23, o que garantiu uma série de mudanças nas relações entre 0 Estado, a comunidade e a sociedade indígena.

O Artigo 196 da Constituição Federal atribuiu ao Estado o dever de oferecer saúde à população como um direito dos cidadãos brasileiros. O Sistema Único de Saúde foi regulamentado pela Lei $n^{0} 8.080 / 90^{24}$, denominada Lei Orgânica de Saúde, que estabeleceu princípios organizacionais do sistema, dentre eles: participação popular, descentralização e hierarquia. O Ministério da Saúde criou a Fundação Nacional de Saúde e a Coordenação de Saúde do Índio (COSAI), à qual caberia a responsabilidade da gestão da saúde indígena, porém, iniciou-se, naquele respectivo momento - em face da instituição dos citados órgãos, um período de dificuldades, as quais foram agravadas pela instituição do "Novo" em face da manutenção do tradicional interesse indígena.

Em 1991, os Decretos Presidenciais n 23, 24, 25 e 2625-28 concederam base legal para a política indigenista, a qual fora proposta na $1^{\text {a }}$ Conferência Nacional de Proteção à Saúde do Índio22, criando-se, assim, o primeiro Distrito Sanitário Indígena (DSEI) e o Distrito Sanitário Yanomami (DSY), no Amazonas e em Roraima.

As reformulações sanitárias indígenas emergiram nos anos 90 e foi aprovada a Lei Arouca n ${ }^{\circ} 9.836{ }^{29}$, criando-se, assim, o Subsistema de Atenção à Saúde Indígena (SASISUS). A responsabilidade da Saúde Indígena passou a ser da União, sendo a gestão administrativa realizada pela Fundação Nacional de Saúde (FUNASA) - Decreto $n^{0} 3.156^{30}$.

Naquele mesmo ano, o projeto de criação do Distrito Sanitário Especial Indígena (DSEI) foi formulado e pautado nos princípios e diretrizes do SASISUS. Foram inseridos, ao todo, 34 DSEls - por causa da diversidade e dos contextos regionais adversos da população indígena -, de modo que coube a este órgão prestar assistência básica, com equipes multidisciplinares, com base no modelo do Programa Saúde da Família. Essas unidades sanitárias operacionais e administrativas exigiram um grande contingente de recursos humanos e financeiros para exercer a gestão administrativa e a execução dos serviços ${ }^{31}$.

Evidentemente, a organização de dados não poderia mais ser postergada, por sua vez, foi criado 0 Sistema de Informação e Atenção à Saúde Indígena (SIASI), o qual consiste em um processamento de análise de informações para 0 acompanhamento da saúde das comunidades indígenas, abrangendo nascimentos, óbitos, morbidades, imunização, produção de serviços, recursos humanos e infraestrutura ${ }^{32}$. Em 2002, um novo sistema fora aprovado, juntamente com a Política Nacional de Atenção à Saúde dos Povos Indígenas, cuja Portaria é de $n^{0} 25433$. 


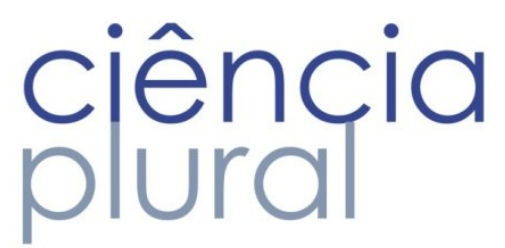

Por causa da necessidade de um modelo de atenção primária destinada às ações preventivas e multidisciplinares, foi criado, em 2004, o Programa Brasil Sorridente, um componente da Política Nacional de Saúde Bucal, que propôs uma série de medidas para facilitar e aumentar o acesso da população ao tratamento odontológico gratuito, por meio do Sistema Único de Saúde 34 .

As ações do Programa Brasil Sorridente trouxeram ganhos para a saúde bucal brasileira, entretanto com relação à saúde bucal indígena havia apenas práticas pontuais. Em 2007, a assistência à saúde bucal indígena foi normatizada pelas "Diretrizes para a Atenção à Saúde Bucal dos Povos Indígenas", a qual orientou o processo dos serviços de saúde bucal dos povos indígenas ${ }^{35}$.

O modelo distrital do SASISUS gerou uma incompatibilidade organizativa diante das diretrizes do Sistema Único de Saúde. A solução para proporcionar a prática de serviços nas aldeias foi a terceirização, a qual fora viabilizada por meio de convênios com prefeituras municipais, organizações indígenas e outras entidades não governamentais ${ }^{36}$. No entanto, as críticas dos povos indígenas aos serviços de saúde prestados pela FUNASA eram de plena insatisfação e a solução foi criar a Secretaria Especial de Saúde Indígena (SESAI), Lei $n^{0} 12.314^{37}$, vinculada ao Ministério da Saúde.

A criação da SESAI foi homologada por meio da publicação do Decreto $n^{0} 7.336$, alterada pelo Decreto $n^{0} 7.461$, e, posteriormente, pelo Decreto $n^{0} 7.530^{38-40}$, o qual esclareceu que o Ministério da Saúde e a FUNASA precisavam efetivar, de forma gradativa, a transição da gestão do Subsistema de Atenção à Saúde Indígena para o MS até o dia 31 de dezembro de 2011.

Este período de transição para a implantação da nova gestão da saúde indígena caracterizou-se por uma gestão compartilhada entre a SESAI e a FUNASA. Embora o governo tivesse determinado um prazo de três meses para o detalhamento de sua estrutura e das demais providências para torná-la operacional, a situação se arrastou por mais de três anos, enquanto a assistência à saúde nas comunidades passava por momentos críticos.

\section{Resultados e Discussão}

A efetiva implementação de políticas públicas, especialmente a de saúde bucal indígena, implica diretamente na dificuldade que possui, tanto os governos, quanto os gestores públicos, na administração dos diversos interesses existentes, mormente quando envolve investimentos e desconsidera-se a cultura tradicional silvícola. Essa situação, por vezes denota a ineficiência do ente público em atingir os objetivos aspirados ${ }^{41}$.

No Brasil, estudos e análises de políticas públicas são tendências relativamente recentes, ainda pouco consolidados e carentes de conhecimento. A própria natureza da área política influencia as variáveis 


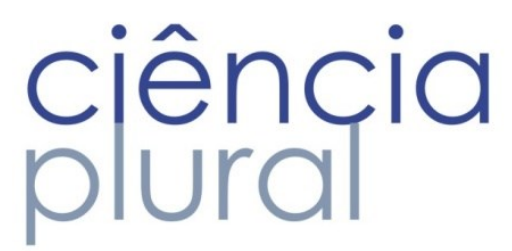

e as dimensões relevantes para uma análise ${ }^{42}$. Nesse contexto, as diferentes abordagens contribuem fortemente para adicionar pontos de vista sobre 0 assunto.

A partir da implantação das novas políticas de saúde, o Ministério da Saúde, em caráter executivo, passou a gerenciar diretamente a saúde dos indígenas, tendo como adjacentes os Distritos Sanitários Especiais Indígenas (DSEls), levando em conta aspectos culturais, étnicos e epidemiológicos dos povos indígenas que vivem no Brasil, o que, em um primeiro momento, era de responsabilidade da FUNASA 43. Com as mudanças estruturais, a configuração do MS ficou disposta da seguinte maneira:

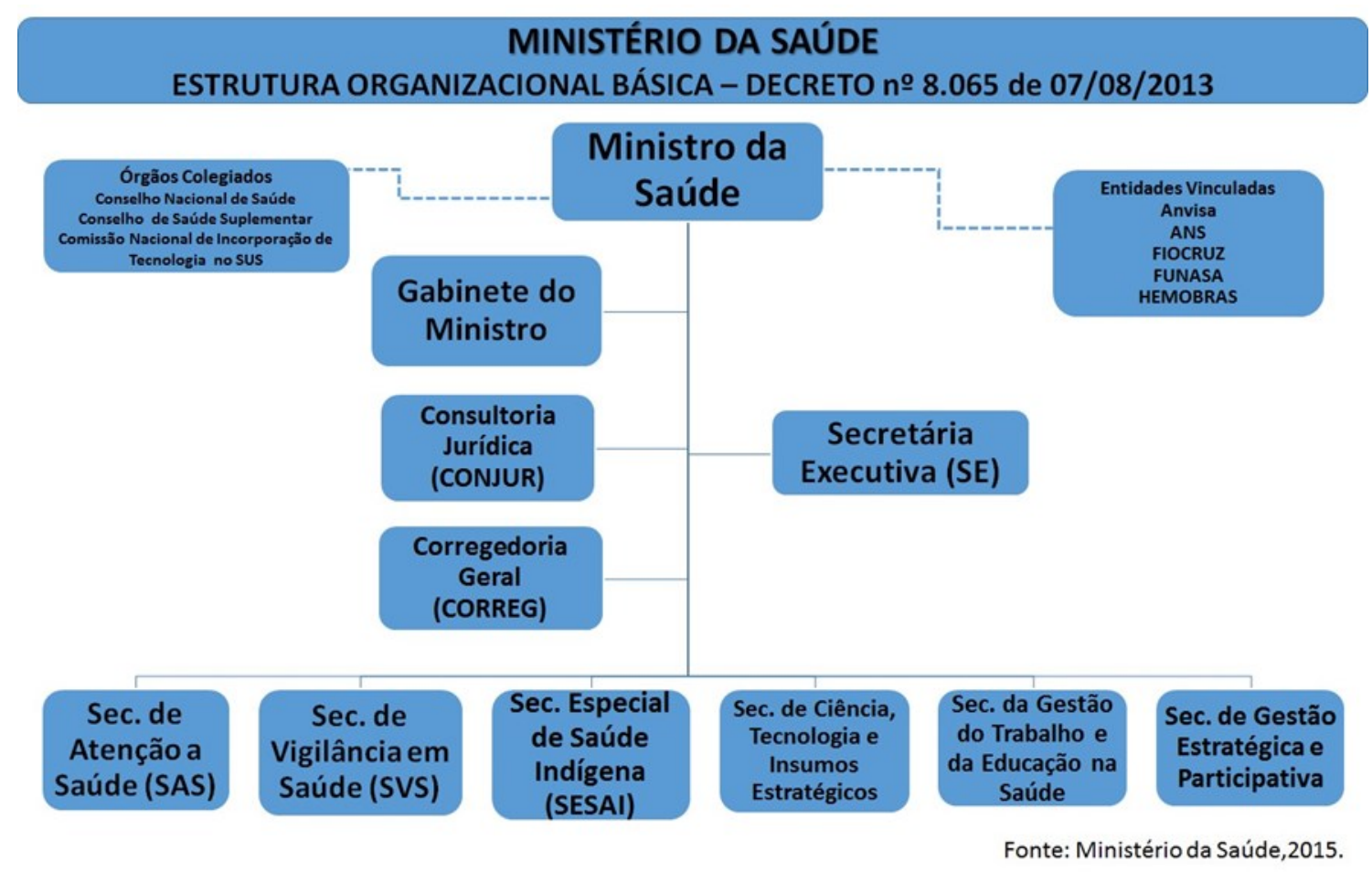

Figura 1: Esquema do Modelo de Organização Subsistema de Atenção à Saúde Indígena. Araçatuba-SP, 2018.

Após as referidas mudanças, a SESAI publicou uma seleção de entidades privadas sem fins lucrativos, para realizar ações de saúde nos povos indígenas. As entidades selecionadas formam a Sociedade Paulista para o Desenvolvimento da Medicina (SPDM), com sede em São Paulo, responsável por 14 Distritos Sanitários Indígenas (DSEls). São eles, o Instituto Materno Infantil de Pernambuco (IMIP), cuja sede está localizada em Recife, responsável por 5 DSEls, e a Missão Evangélica Caiuá, cuja sede é em Campo Grande, responsável por 15 DSEls $32,43$.

Para se tornar um modelo descentralizado e hierárquico, a estrutura das unidades gestoras - DSEls foi baseada no modelo de Unidades de Saúde nas aldeias indígenas, ou seja, Polo-Base em territórios 


\section{ciência \\ plural}

indígenas e a Casa de Saúde Indígena CASAI), demonstrado na figura 2. Desta forma, buscou-se conferir uma efetividade administrativa de forma a implementar os interesses silvícolas.

Apesar das diferentes áreas territoriais indígenas, elas foram criadas em pontos estratégicos, junto à localização dos DSEls ou de grandes centros de referência ${ }^{32}$.

\section{Organização do DSEl e Modelo Assistencial}

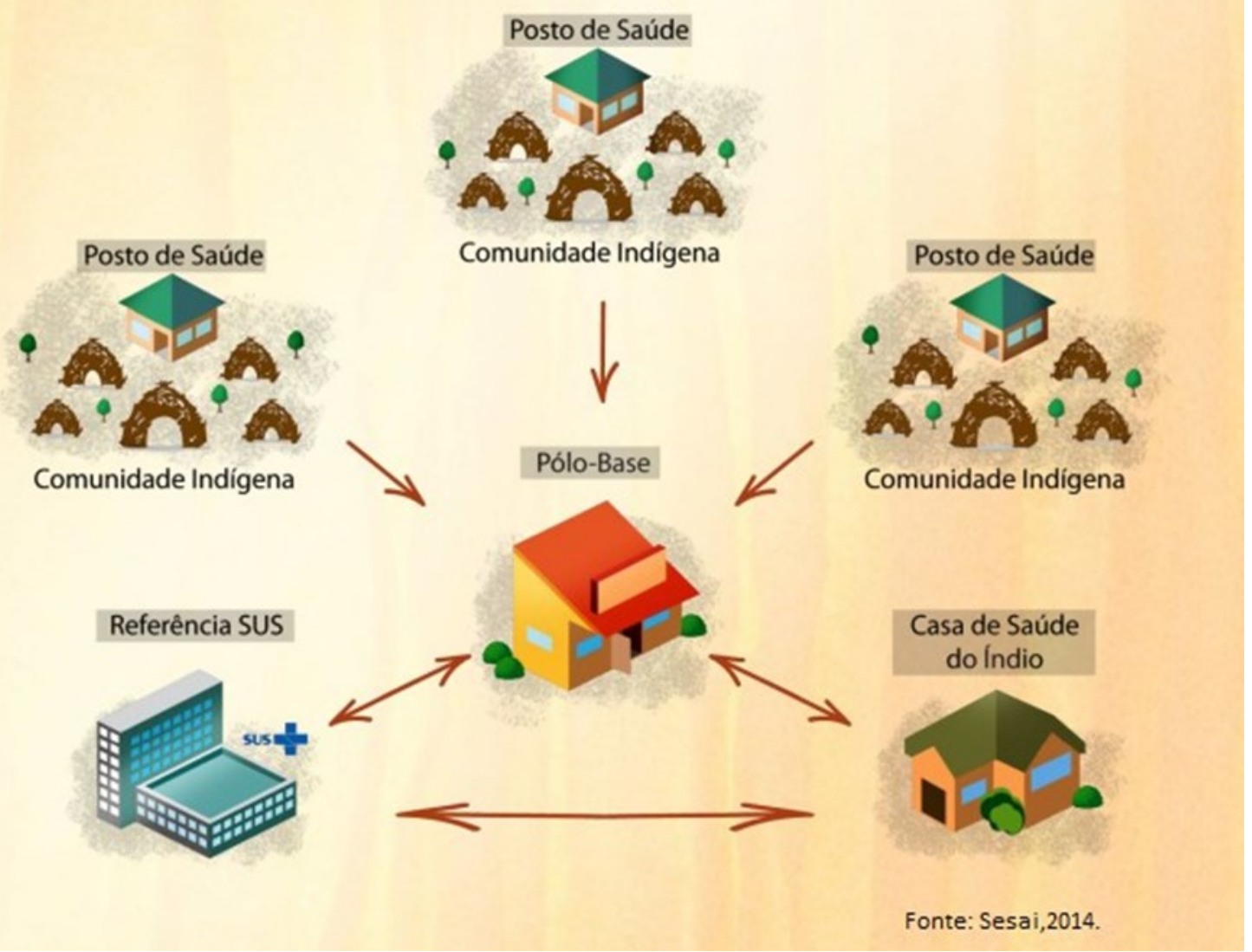

Figura 2: Esquema do Modelo de Organização Subsistema de Atenção à Saúde Indígena. Araçatuba-SP, 2018.

As diretrizes da Política Nacional de Atenção à Saúde dos Povos Indígenas (PNASPI), do Sistema Único de Saúde e do Subsistema de Atenção à Saúde Indígena, são modelos de assistência que entendem o processo saúde-doença de forma coletiva e multifatorial ${ }^{35}$. A concepção dessa política enfatiza a educação em saúde, bem como as ações preventivas e promotoras de saúde, entretanto, as ações de saúde bucal eram descontinuadas e fragmentadas. Não havia garantia da integralidade do cuidado, com organização entre os níveis de atenção, que proporcionasse a resolutividade no serviço.

O primeiro passo para a melhoria da saúde bucal indígena consistiu na implementação do Componente Indígena da Política Nacional de Saúde Bucal44, após a criação do Programa Brasil Sorridente. 


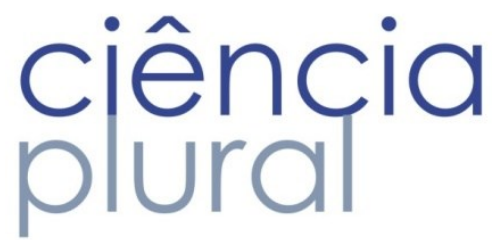

Em 2011, foi lançado o Programa Brasil Sorridente Indígena ${ }^{45}$, cujo objetivo era levar atendimento às aldeias indígenas, estruturando e qualificando os serviços de saúde bucal nos DSEls.

O Programa Brasil Sorridente Indígena foi executado em duas etapas: inicialmente, o Ministério da Saúde adquiriu 37 consultórios odontológicos portáteis para aparelhar as equipes de saúde, com duração de seis meses; fase que repôs as necessidades das comunidades indígenas em três DSEls: em XavanteMT, em Alto Purus - nos Estados do Acre, Amazonas e Roraima - e em Alto Rio Solimões-AM, sendo estes os três maiores distritos. Posteriormente, com a intenção de reorganizar 0 atendimento integral em saúde bucal em todos os 34 DSEl do país, o Ministério da Saúde investiu na compra de consultórios portáteis e kits instrumentais para equipar 514 equipes de saúde bucal. As medidas foram previstas no Brasil Sorridente Indígena, coordenadas pelo Ministério da Saúde e executadas pelos DSEls ${ }^{45}$.

Na 5 a Conferência Nacional de Saúde Indígena, realizada em 2014, a discussão em relação à saúde bucal teve como seu principal destaque a implantação do Programa Brasil Sorridente Indígena, cuja finalidade era a de levar ações realizadas na saúde bucal para atender as medidas tomadas pelo programa. A discussão foi longa quanto às questões que garantiriam 0 aumento do recurso financeiro, o acompanhamento, a monitoração e a avaliação das ações de saúde destinadas ao atendimento odontológico da população indígena, que manteriam a oferta permanente de medicamentos e outros insumos, e a maneira como poderia ser aprimorada a logística com carros, barcos, aeronaves, saneamento, controle social, de equipamentos médico-hospitalares e odontológicos no âmbito do SASISUS 46 .

Apesar dos avanços, alguns autores apresentam recorrentes disparidades na saúde em comparação à população brasileira não indígena. Essa diferença é observada nos perfis de saúde indígena, nos níveis nacionais e regionais, em uma combinação de fatores socioeconômicos, ambientais e políticos ${ }^{7,47}$. Um dos desafios das Conferências Indígenas é impulsionar a discussão sobre a autonomia dos DSEls na execução de ações relacionadas à saúde nas aldeias, incentivando a participação da comunidade para melhoria de resultados?

Segundo Dalfior ${ }^{41}$, é fundamental uma discussão da microgestão do governo, no âmbito do processamento da política, uma vez que é no nível local que os ajustes são realizados para alcançar as prerrogativas delineadas. Nesse sentido, para que uma política pública seja implementada, é necessário traduzi-la como uma política institucional e organizacional. Para tal, há a necessidade das conferências para expor os resultados, as problemáticas e as novas propostas dessas políticas.

Os resultados dessa análise foram demonstrados na figura 3, de modo cronológico, baseados na história política, nas políticas públicas de saúde e nas políticas indigenista. 


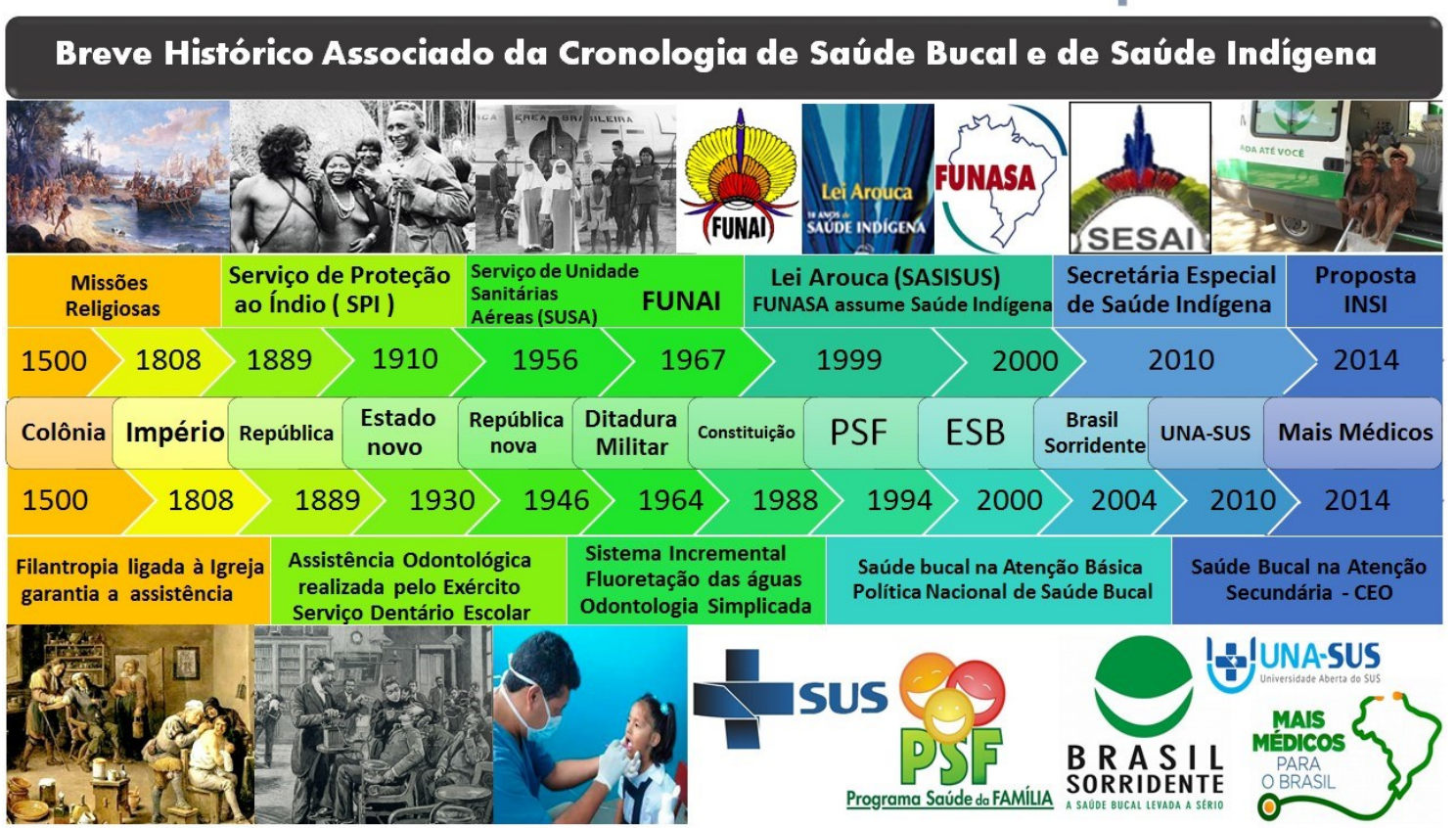

Figura 3: Sequência Cronológica da Saúde Bucal e Saúde Indígena. Araçatuba-SP, 2018.

O Ministério da Saúde propôs o Projeto de Lei $n^{0} 3501 / 2015^{48}$, que "autoriza o Poder Federal a instituir o serviço autônomo - denominado Instituto Nacional de Saúde Indígena - INSI", com objetivo de executar diretamente as ações e os serviços de promoção, proteção e recuperação da saúde indígena, bem como ações de saneamento ambiental e de edificações de saúde indígena no âmbito do Subsistema de Atenção à Saúde Indígena ${ }^{48}$; proposta que não foi colocada em pauta na discussão na $5^{\text {a }}$ Conferência Nacional de Saúde Indígena.

A escolha pela forma de serviço social autônomo justifica-se pela necessidade de adoção de um modelo que possibilite uma abordagem diferenciada e global do tema, possibilitando, também, novas alternativas de contratação de pessoal, mediante processo seletivo, com critérios diferenciados de acesso. 0 principal desafio enfrentado pelo segmento refere-se à permanência de um quadro de profissionais que permita atendimento efetivo às necessidades das comunidades indígenas ${ }^{48}$.

Muito embora verifica-se que seja louvável, por parte do Ministério da Saúde, especialmente pela externalização dos seus motivos, a defesa da criação do INSI, o movimento indígena considera um mecanismo de privatização da saúde silvícola. Com isso, não haverá nenhuma tutela das minorias e muito menos os fins serão observados. De modo contrário, e por força da consulta pública e livre direcionada pela $6^{\text {a }}$ Câmara de Coordenação e Revisão do Ministério Público Federal ${ }^{49}$ (que vem a ser o órgão que cuida deste tema (índios, minorias e quilombolas) o MPF não apoia a criação do INSI, ou seja, o Instituto Nacional de Saúde Indígena. 


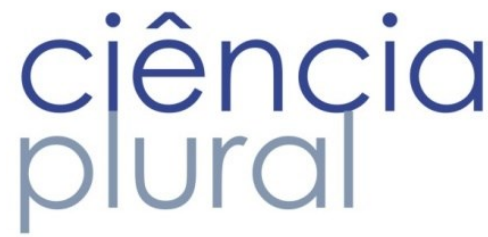

A implementação de novos serviços deve ser reconhecida como uma etapa fundamental das políticas públicas, sendo primordial buscar e analisar como os arranjos se comportam frente a uma determinação governamental para implementar ações, programas e políticas ${ }^{50}$. Torna-se necessário, assim, compreender o que leva os agentes implementadores de políticas públicas a torná-las realidade, objetivando efetivar e alcançar as finalidades formuladas, de forma que sejam incorporadas e possam colaborar na solução de entraves que dificultam a implementação, bem como é necessário reforçar as estratégias e experiências de sucesso de tais políticas.

A saúde indígena é complexa e as dificuldades para a sua eficiência são inúmeras, como 0 acesso às comunidades, a diversidade e as especificidades de cada grupo étnico, a falta de profissionais qualificados, a estrutura organizacional e a gestão participativa, dentre outras. Os problemas de implantação de serviços diferenciados e de forma duradoura perduram nessa área. Nessa lógica, a implementação de novas políticas públicas deve ser reconhecida como um passo fundamental para a evolução das ações, dos programas e consequentemente para a garantia da saúde da população indígena.

\section{Conclusão}

A análise documental, de série histórica e legal da saúde indígena, demonstrou relação lógica entre esses dois aspectos e, de forma concisa, as estratégias utilizadas nas políticas públicas de saúde. A trajetória da saúde bucal da população indígena brasileira é marcada por enfrentamentos e embora existam bases jurídicas que garantem 0 acesso aos cuidados à saúde, a descontinuidade das políticas públicas silvícolas impede a efetividade e a tutela dos seus interesses, em detrimento de sua singularidade, especialmente no que tange ao dilema cultura e respeito às minorias.

\section{Referências}

1. Instituto Brasileiro De Geografia E Estatística (IBGE). Os Indígenas no censo demográfico 2010: primeiras considerações com base no quesito cor ou raça. Rio de Janeiro: IBGE; 2012. [citado em: $10 \mathrm{dez}$. 2017]. Disponivel em: em:https://indigenas.ibge.gov.br/images/indigenas/estudos/indigena_cens02010.pdf.

2. Organização Das Nações Unidas (OMS). Declaração das Nações Unidas sobre os Direitos dos Povos Indígenas. Rio de Janeiro: Nações Unidas; 2008.

3. Garnelo, L. Política de Saúde Indígena no Brasil: notas sobre as tendências atuais do processo de implantação do subsistema de atenção à saúde. In: Garnelo L, Pontes AL, organizadores. Saúde indígena: uma introdução ao tema. Brasília: Mec-Secadi; 2012; p.18-6.

4. Arantes R, Santos RV, Frazão P. Oral health in transition: the case of Indigenous peoples from Brazil. Int Dent J. 2010; 60(3 suppl 2):235-40. 


\section{ciência plural}

5. Cardoso, MD. Saúde e povos indígenas no Brasil: notas sobre alguns temas equívocos na política atual. Cad Saúde Pública. 2014; 30(4):860-6.

6. Coimbra Junior CEA, Santos RV. Minorias e desigualdades: algumas teias de inter-relações, com ênfase nos povos indígenas no Brasil. Ciên Saúde Colet. 2000; 5(1):125-32.

7. Coimbra Junior CEA. Saúde e povos indígenas no Brasil: reflexões a partir do I Inquérito Nacional de Saúde e Nutrição Indígena. Cad Saúde Pública. 2014; 30(4): 855-859.

8. Moimaz, SAS Saliba NA, Garbin CAS, Bergamaschi Júnior E, Souza JEA. Percepção de saúde bucal em uma comunidade indígena no Brasil. Rev Fac Odonto Lins. 2001; 13(1):60-5.

9. Sousa MC, Scatena JHG, Santos RV. O Sistema de informação da atenção à saúde Indígena (SIASI): criação, estrutura e funcionamento. Cad Saúde Pública. 2007; 23(4):853-61.

10. Moimaz SAS, Zina LG. Manual de odontologia baseada em evidência e revisão sistemática. Araçatuba: Programa de Pós-graduação em Odontologia Preventiva e Social; 2008.

11. Bardin L. Análise de conteúdo. Lisboa: Edições 70; 2011.

12. Confaloniere UEC. O Sistema Único de Saúde e as populações indígenas: por uma integração diferenciada. Cad Saúde Pública. 1989; 5(4):441-50.

13. Azevedo, M. Demografia dos povos indígenas do Alto Rio Negro. Rev Bras Estudos Pop. 1994; 11(2):235-44.

14. Brasil. Decreto $n^{0} 8.072$, de 20 de junho de 1910. Crêa o Serviço de Protecção aos Indios e Localização de Trabalhadores Nacionaes e aprova o respectivo regulamento. Diário Oficial da União. 24 jun 1910; seção 1: 4788.

15. Garnelo L, Macedo G, Brandão LC. Os povos indígenas e a construção das políticas de saúde indígena no Brasil. Brasília: Organização Pan- Americana da Saúde; 2003.

16. Nutels N. SUSA - 1959. Resumo das atividades durante o ano passado, Rio de Janeiro, Serviço Nacional da Tuberculose. Rev SNT. 1960; 4:27-35.

17. Costa DC. Política indigenista e assistência à saúde: Noel Nutels e o serviço de unidades sanitárias aéreas. Cad Saúde Pública. 1987; 3(4):338-401.

18. Brasil. Lei $\mathrm{n}^{0} 5.371$, de 5 de dezembro de 1967. Autoriza a instituição da "Fundação Nacional do Índio" e dá outras providências. Diário Oficial da União. 06 dez 1967; Seção 1: 12223.

19. Brasil. Lei $n^{\circ} 6.001$, de 19 de dezembro de 1973. Dispõe sobre o Estatuto do Índio. Diário Oficial da União. 21 dez 1973; Seção 1:13177.

20. Fundação Nacional Do Índio (FUNAI). Índios no Brasil: quem são. 2015. [Citado em: 10 dez. 2017]. Disponivel em: http://www.funai.gov.br/index.php/indios-no-brasil/quem-sao.

21. Manfredini MA. Saúde bucal no Brasil em 2008 e nos 20 anos de sistema único de saúde. In: Brasil. Ministério da Saúde. Saúde Brasil 2008: 20 anos de Sistema Único de Saúde (SUS) no Brasil. Brasília: Ministério da Saúde; 2009. p. 155-74.

22. Brasil. Ministério da Saúde. Conselho Nacional de Saúde. $1^{\text {a }}$ Conferência Nacional de Saúde Bucal: relatório final. Brasília: Ministério da Saúde; 1986. [citado em: 10 dez 2017]. Disponivel: http://conselho.saude.gov.br/biblioteca/Relatorios/relatoriolconferencianacionaldesaudebnucal.

23. Brasil. Constituição Federal de 1988. Brasília: Congresso Nacional; 1988. [citado em: 10 dez 2017]. Disponível em: http://www.alep.pr.gov.br/system/files/corpo/Con1988br. 


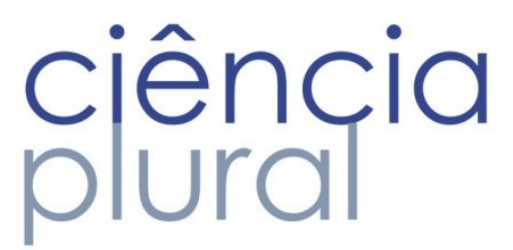

24. Brasil. Lei n $n^{\circ} 8.080$, de 19 de setembro de 1990. Lei Orgânica da Saúde. Dispõe sobre as condições para promoção, proteção e recuperação da saúde, a organização e o funcionamento dos serviços correspondentes e dá outras providências. Diário Oficial da União. 20 set 1990; Seção 1:18055.

25. Brasil. Decreto $n^{0} 23$, de 4 de fevereiro de 1991. Dispõe sobre as condições para a prestação de assistência à saúde das populações indígenas. Diário Oficial da União; 1991. [citado 10 dez 2017]. Disponível em: http://www.planalto.gov.br/ccivil_03/decreto/1990-1994/D0023.

26. Brasil. Decreto $n^{0} 24$, de 4 de fevereiro de 1991. Dispõe sobre as ações visando a proteção do meio ambiente em terras indígenas. Diário oficial da União; 1991. [citado em: 10 dez 2017]. Disponível em: http://www.planalto.gov.br/ccivil_03/decreto/1990-1994/D0026.

27. Brasil. Decreto $n^{0} 25$, de 4 de fevereiro de 1991. Dispõe sobre programas e projetos para assegurar a auto-sustentação dos povos indígenas. Diário Oficial da União; 1991. [citado em: 10 dez 2017]. Disponível em: http://www.planalto.gov.br/ccivil_03/decreto/1990-1994/D0025.

28. Brasil. Decreto $n^{0} 26$, de 4 de fevereiro de 1991. Dispõe sobre a Educação Indígena no Brasil. Diário Oficial da União; 1991. [citado em: 10 dez 2017]. Disponivel em: http://www.planalto.gov.br/ccivil_03/decreto/1990-1994/D0026.

29. Brasil. Lei $n^{0} 9.836$, de 23 de setembro de 1999. Acrescenta dispositivos à Lei $n^{0} 8.080$, de 19 de setembro de 1990, que "dispõe sobre as condições para a promoção, proteção e recuperação da saúde, a organização e o funcionamento dos serviços correspondentes e dá outras providências", instituindo 0 Subsistema de Atenção à Saúde Indígena. Diário Oficial da União. 24 set 1999; Seção 1:1

30. Brasil. Decreto $n^{0} 3.156$, de 27 de agosto de 1999. Dispõe sobre as condições para a prestação de assistência à saúde dos povos indígenas, no âmbito do Sistema Único de Saúde, pelo Ministério da Saúde, altera dispositivos dos Decretos n 564 , de 8 de junho de 1992, e 1.141, de 19 de maio de 1994, e dá outras providências. Diário Oficial da União. 28 ago 1999; Seção 1:37.

31. Garnelo L. Política de Saúde dos Povos Indígenas no Brasil: análise situacional do período de 1990 a 2004. 2004. [citado em 10 dez 2017]. Disponivel em: http://www.cesir.unir.br/pdfs/doc9.

32. Sousa MC, Scatena JHG, Santos RVO. Sistema de Informação da Atenção à Saúde Indígena (SIASI): criação, estrutura e funcionamento. Cad Saúde Pública. 2007; 23(4):853-61.

33. Brasil. Ministério da Saúde. Portaria $\mathrm{n}^{0} 254$, de 31 de janeiro de 2002. Aprova a política nacional de atenção à saúde dos povos Indígenas. Diário Oficial União; 2002. [citado em: 10 dez 2017]. Disponível em: http://www.funasa.gov.br/site/wp-contentfiles_mf/Pm_254_2002.pdf.

34. Brasil. Ministério da Saúde. Diretrizes da política nacional de saúde bucal. Brasília: Ministério da Saúde; 2004.

35. Brasil. Ministério da Saúde. Diretrizes para a atenção à saúde bucal nos Distritos Sanitários Especiais Indígenas: manual técnico. Brasilia: Ministério da Saúde; 2007.

36. Garnelo L, Sampaio S. Bases sócio-culturais do controle social em saúde indígena. Problemas e questões na Região Norte do Brasil. Cad Saúde Pública. 2003; 19(1):311-317.

37. Brasil. Ministério da Saúde. Lei $n^{0} 12.314$, de 19 de agosto de 2010, que autoriza a criação da Secretaria Especial de Saúde Indígena (SESAl) no âmbito do Ministério da Saúde. Diário oficial de União; 2010. [citado em: 10 dez 2017]. Disponível em: http://www.planalto.gov.br/ccivil_03/_Ato20072010/2010/Lei/L12314.htm. 


\section{ciência plural}

38. Brasil. Decreto $n^{0} 7.336$ de 19 de outubro de 2010. Aprova a Estrutura Regimental e o Quadro Demonstrativo dos Cargos em Comissão e das Funções Gratificadas do Ministério da Saúde, e dá outras providências. Diário Oficial da União. 20 out 2010; Seção 1:6

39. Brasil. Decreto $n^{0} 7.461$ de 18 de abril de 2011. Dá nova redação ao caput do art. 60 do Decreto no 7.336, de 19 de outubro de 2010, para prorrogar o prazo de efetivação da transição da gestão do Subsistema de Atenção à Saúde Indígena da Fundação Nacional de Saúde para o Ministério da Saúde. Diário Oficial União. 19 abr 2011. [citado em: 10 dez 2017]. Disponível em: http://www.planalto.gov.br/ccivil_03/_ato2011-2014/2011/decreto/d7461.htm.

40. Brasil. Decreto $n^{0} 7.530$ de 21 de julho de 2011. Aprova a Estrutura Regimental e o Quadro Demonstrativo dos Cargos em Comissão e das Funções Gratificadas do Ministério da Saúde. Diário Oficial da União. 22 jul 2011; Seção 1:9.

41. Dalfior ET, Lima RCD, Andrade MAC. Reflexões sobre análise de implementação de políticas de saúde. Saúde Debate. 2009; 39(104):210-225.

42. Viana LA, Baptista TWF. Análise de políticas de Saúde. In: Giovanella L, Organizador. Políticas e Sistema de Saúde no Brasil. Rio de Janeiro: Ed. Fiocruz; 2009. p. 65-105.

43. Chaves MBG, Cardoso AM, Almeida C. Implementação da política de saúde indígena no Polo-Base Angra dos Reis, Rio de Janeiro, Brasil: Entraves e perspectivas. Cad Saúde Pública. 2006; 22(2):295-305.

44. Brasil. Ministério da Saúde. Diretrizes do componente indígena da Política Nacional de Saúde Bucal. Brasília: Ministério da Saúde; 2011. Disponível em: http://189.28.128.100/dab/docs/ publicacoes/geral/diretriz_indigena. Acesso em 10 dez.2017.

45. Brasil. Ministério da Saúde. Portal da Saúde. Cidadão. Agência de Saúde. Saúde lança Brasil Sorridente Indígena. 2011. [citado em: 10 dez. 2017]. Disponível em: http://portalsaude.saude.gov.br/index.php/cidadao/principal/agencia-saude/noticias-anteriores-agenciasaude/5116-saude-lanca-brasil-sorridente-indigena.

46. Brasil. Ministério da Saúde. Conselho Nacional de Saúde. $5^{\text {a }}$ Conferência Nacional de Saúde Indígena: relatório final. Brasília: Ministério da Saúde; 2014. [citado em: 10 dez.2017]. Disponível em: http://conselho.saude.gov.br/biblioteca/Relatorios/02fev_01_relatorio_final_5cnsi.

47. Welch JR. Fórum: saúde e povos indígenas no Brasil. Introdução. Cad. Saúde Pública. 2014; 30(4): 851-854.

48. Brasil. Projeto de Lei $n^{0} 3.501$, de 3 de novembro 2015. Autoriza o Poder Executivo federal a instituir serviço social autônomo denominado Instituto Nacional de Saúde Indígena. 2015. [citado em: 10 dez. 2017]. Disponível em: http://www.planalto.gov.br/CCIVIL_03/Projetos/PL/2015/msg460-outubro2015.

49. Brasil. Ministério Público Federal. Nota pública PGR. 199850-2014. $6^{\text {a }}$ Câmara de Coordenação e Revisão. Populações Indígenas e Comunidades Tradicionais. 2014. [citado em: 10 dez. 2017]. Disponível em: $\quad$ http://www.mpf.mp.br/atuacao-tematica/ccr6/dados-da-atuacao/grupos-de-trabalho/gtsaude/docs/docs_documentos_gt/nota-insi.

50. Dalfior ET, Lima RCD, Andrade MAC. Implementação de políticas públicas: metodologia de análise sob o enfoque da política institucional. Saúde debate. 2015; 39:283-297. 